\title{
The Influence of Ownership Structure on Firms' R\&D Investments: An Empirical Investigation
}

\author{
Zhi-Hong Song, Xue Wang, and Dong-Mei Lee
}

\section{ABSTRACT}

\begin{abstract}
By using listed companies of Shanghai Stock Exchange in the coal-mining industry as samples, this paper empirically tests the influence of ownership structure on firms' R\&D investments. Firstly, the influence mechanism of ownership structure on $R \& D$ investments is analyzed based on the principalagent theory, and hypotheses are developed accordingly. Then, the empirical analyses are conducted based on data from China Stock Market \& Accounting Research Database. The empirical results show that the degree of ownership concentration has a negative impact on firms' R\&D investments, and the improvement of equity counterbalance has a positive effect on firms' $R \& D$ investments. The state-owned enterprises' firms' $R \& D$ investments is higher than that of privately-owned enterprises. The highly concentrated ownership mode of state-owned shares may hinder their investment in firms' R\&D investments to some extent.
\end{abstract}

Keywords: Equity Concentration, Equity Counterbalance, Equity Nature, R\&D Investments.

\section{INTRODUCTION}

The nature of equity can be categorized as state-owned and privately-owned according to the ultimate ownership of control rights. Other things being equal, the motivation and performance of privately-owned enterprises in $R \& D$ investment are obviously stronger than that of state-owned enterprises [1]. As the technological innovation in the American energy industry was more driven by the government, the incentive for enterprises to invest in innovation projects was greatly reduced [2], [3]. In addition, legal holdings had positive effects on R\&D investments [4].

Some research showed that, the stronger the synergy effect between the interests of major shareholders and enterprises, the more motivated they are to supervise and restrain managers and increase the intensity of R\&D investments in order to obtain higher returns [5]-[7]. Some scholars have found that the degree of ownership concentration has a significant positive effect on firms' $R \& D$ investment, and major shareholders are keen to obtain long-term profits and high returns to support R\&D activities [8].

To sum up, previous literature has failed to reach a consistent view on the relationship between ownership structure and firms' R\&D investments. So, a more comprehensive and in-depth research is still needed to reach a more consistent conclusion. In this paper, listed companies of Shanghai Stock Exchange in the coal-mining industry are selected as the research samples, with the aim of providing a useful supplement to the existing literature.
Submitted : June 15,2021

Published : July 15, 2021

ISSN: $2507-1076$

DOI: $10.24018 /$ ejbmr.2021.6.4.937

\section{Zhi-Hong Song *}

Institute of Management and Decision, Shanxi University, Taiyuan, P. R. China.

(e-mail: songzhihong ${ }^{\circledR}$ sxu.edu.cn)

Xue Wang

School of Economics and Management, Shanxi University, Taiyuan, P. R. China.

(e-mail: 1425656637@qq.com)

Dong-Mei Lee

School of Economics and Management Shanxi University, Taiyuan, P. R. China.

(e-mail: lidm@sxu.edu.cn)

*Corresponding Author

\section{THEORY AND HYPOTHESES DEVELOPMENT}

\section{A. The Relationship between the Degree of Ownership Concentration and $R \& D$ Investments}

The degree of ownership concentration is an indicator that reflects the distribution pattern of corporate voting rights. Ownership patterns can be divided into three types: decentralization, moderate concentration, and high concentration. In the case of decentralized ownership, the agency problem between shareholders and managers is dominant. Due to the existence of many small and medium shareholders, there is a large gap between their supervision costs and benefits, which is likely to lead to speculation and free riding problem among shareholders, making the enterprise actually controlled by the managers, while their "short-sighted behavior" results in the lack of initiative of enterprises to invest in $\mathrm{R} \& \mathrm{D}$ [9]. The more concentrated the degree of ownership, the more incentive the shareholders have to restrain the managers. When the majority shareholders are unable to capture the control benefits, $R \& D$ investments will be higher. When the equity is relatively concentrated, the majority shareholder can exercise strong supervision over the managers. In order to maintain or improve their position, they may conduct some short-term actions that may harm the operation efficiency of the enterprises. In addition, the majority shareholder can also rely on its controlling position to seek control gains, thus lacking the motivation to innovate. In this case, the more concentrated the equity, the lower the R\&D investments will be. In this case, the majority shareholder, as the owner of the enterprise, 
will take a positive attitude towards the R\&D activities that can bring long-term returns. Thus, we have the following hypothesis:

$\mathrm{H} 1$ : there is an " $\mathrm{N}$ " type non-linear relationship between ownership concentration and R\&D investments of enterprises.

\section{B. The Relationship between Equity Counterbalance and $R \& D$ Investments}

The degree of equity counterbalance refers to the equity distribution patterns where the major shareholders restrict each other in order to ensure the maximization of their own rights and interests. When the equity is more dispersed, the function of supervision and counterbalance is neither apparent nor meaningful. However, if the equity is more concentrated, this function is further highlighted. When the ownership is relatively concentrated, the function of supervision and counterbalance can play a dominant role for the majority shareholders over the managers. To a certain extent, the R\&D investments will change in the same direction. However, too much supervision and counterbalance will reduce the gap between shareholders' share holdings [2]-[4]. As shareholders have different views on the development prospects of the enterprises, they are prone to engage in power struggles among themselves, which will have a negative impact on the $R \& D$ investments. It also indicates that the controlling shareholders' voting rights in the enterprise will decrease, and the excessive equalization of the controlling shares will form a decentralized structure of equity under high controlling shares, which will reduce the R\&D investments. Thus, we have the following hypothesis:

$\mathrm{H} 2$ : There is an inverted " $\mathrm{U}$ " nonlinear relationship between equity counterbalance degree and R\&D investments.

\section{The Relationship between the Nature of Equity and $R \& D$ Investments}

According to the different types of ultimate controllers, listed companies in China can be divided into state-owned enterprises and privately-owned enterprises. State-owned enterprises are generally controlled by the central or local government, which is likely to cause the phenomenon of "integration of government administration with enterprise". Their business objectives are not only to maximize profits, but also to achieve some political objectives, which may not be closely related to the value-added of listed companies. On the contrary, listed companies shelve their R\&D investments in order to achieve these objectives, distorting the optimal use of funds. Moreover, the poor operation of state-owned enterprises is easy to obtain the support of the government's preferential policies, thus the managers lack the motivation to invest in R\&D activities. Secondly, the principal-agent relationship and the existence of information asymmetry have caused the subject of property rights of state-owned enterprises to be fictitious, the state-owned shareholders lack both incentives and information to effectively supervise the decision-making of the managers, leaving the control of the enterprises in the hands of the managers, who are often concerned about maximizing their own interests or short-term gains in pursuit of re-election, and lack the motivation for technological innovation [6]. As for not-state-owned enterprises, the property right relationship is relatively clear. They are responsible for their own profits and losses, and they bear all the interests and risks. Their business objective is to maximize economic benefits. In order to strengthen their market competitiveness and long-term development prospects, enterprises will increase their R\&D investments. Thus, we have the following hypothesis:

H3: State-owned enterprises' R\&D investments are lower than that of the not-state-owned enterprises.

\section{EMPIRICAL ANALYSES}

\section{A. Data and Variables}

Based on the industry classification standard of the China Securities Regulatory Commission in 2012, this paper takes the cross-sectional data of listed companies in the coal industry in 2014 as the samples, and finally obtains 26 listed companies of Shanghai Stock Exchange in the coal-mining industry. The data of relevant variables are all taken from China Stock Market \& Accounting Research Database.

\section{Dependent variables}

The variable of $R \& D$ investments is measured by $R \& D$ intensity. Due to the incomplete disclosure of $R \& D$ expenses, we select other paid cash flows related to the business activities as a proxy. The natural logarithm of this term is used as the variable in the model construction. The measurement indicators of $R \& D$ investment intensity mainly include $R \& D$ investment compared with stock market value, profit, sales, total assets, etc. As compared with the former three, the total assets of enterprises are more stable.

\section{Independent variables}

This paper uses the first largest shareholder's controlling share (CR1) to measure the degree of ownership concentration.

The degree of equity counterbalance is measured by using the sum of the controlling shares of the second to tenth largest shareholders (EQUITY1).

In terms of the nature of equity (EQUITY2), a dummy variable is used with state-owned enterprises of 1 , and otherwise 0 .

\section{Control variables}

One control variable is enterprise size (SIZE). "Schumpeter Hypothesis" stated the relationship between firm size and technological innovation. Since then, the former has been considered as an important factor affecting the latter. This paper takes the natural logarithm of year-end operating income as a proxy for firm size. Second is control variable of corporate liabilities (DEBT). Debt status also plays an important role in the research and development activities of enterprises, which is represented by the asset-liability ratio of enterprises.

\section{B. Empirical Results}

\section{Descriptive Statistics of Variables}

Table 1shows the descriptive statistical results of each variable. It can be seen that the mean of the absolute amount of R\&D investment is 19.746 and the median is 19.516 , and the mean of the ratio of $R \& D$ investment to total assets is 0.023 and the median is 0.016 , both of which are small, indicating that enterprises in the coal-mining industry do not pay enough attention to $R \& D$ investment in general. 
In terms of the degree of ownership concentration (CR1), the maximum value is $73.83 \%$ and the median is $57.41 \%$, and the data are mainly in the range of $40 \%-60 \%$. Generally speaking, the ownership distribution of sample enterprises is more concentrated. Lin (2005) subdivided three types of holding patterns: absolute holding $(50 \% \leq \mathrm{CR} 1)$, relative holding $(20 \% \leq \mathrm{CR} 1<50 \%)$ and dispersed shareholding (CR1 $<20 \%)$. According to this classification, the number of sample enterprises belonging to three types is 17,8 and 1 respectively. In terms of the degree of equity counterbalance(S), the maximum value is $40.14 \%$, the minimum value is only $1.06 \%$, and the mean value is $13.82 \%$. The average value of the degree of equity counterbalance is even less than $1 / 4$ of the average value of CR1, and the largest shareholder has the absolute right on the operation and decision-making of the enterprise. In terms of equity nature, most of the sample enterprises are controlled by the central government (4) or local government (19), and there are only
3 non-state-owned enterprises. On the whole, the phenomenon of the single dominant share in the coal-mining industry is quite prominent, and the effect of small and medium-sized shareholders' counterbalance on the major shareholders is poor. There are certain policy reasons for the formation of this ownership structure. In 2006, the relevant documents issued by the State-owned Assets Supervision and Administration Commission (SASAC) pointed out that the influence of the state-owned economy must be ensured in seven industries, including the coal-mining industry. In 2008, when the financial crisis broke out, the central government issued a series of macro-control policies, which causing the state-owned capital in these several industries by virtue of its monopoly advantage to accelerate the expansion of mergers and reorganizations at low cost. The coal-mining industry is no exception. Therefore, it is not difficult to understand why the sample enterprises in the coal-mining industry are almost all state-owned enterprises.

TABLE I: DESCRIPTIVE STATISTICS

\begin{tabular}{|c|c|c|c|c|c|c|}
\hline & $\mathrm{N}$ & Minimumvalue & Maximum value & Mean & Median & standard deviation \\
\hline R\&D1 & 26 & 17.9952 & 21.9893 & 19.7459 & 19.5160 & 0.9672 \\
\hline $\mathrm{R} \& \mathrm{D} 2$ & 26 & 0.0024 & 0.0752 & 0.0232 & 0.0163 & 0.0198 \\
\hline CR1 & 26 & 10.9900 & 73.8300 & 54.1812 & 57.4100 & 13.1182 \\
\hline EQUITY1 & 26 & 1.0625 & 40.1400 & 13.8184 & 8.5375 & 11.6561 \\
\hline EQUITY2 & 26 & 0.0000 & 1.0000 & 0.8846 & 1.0000 & 0.3258 \\
\hline SIZE & 26 & 19.5854 & 25.9726 & 22.6655 & 22.5581 & 1.3429 \\
\hline DEBT & 26 & 0.1703 & 0.8139 & 0.5246 & 0.5321 & 0.14490 \\
\hline
\end{tabular}

TABLE II: CORRELATION MATRIX

\begin{tabular}{ccccccc}
\hline \hline & R\&D1 & R\&D2 & CR1 & EQUITY1 & EQUITY2 & SIZE \\
\hline \hline R\&D1 & - & & & & & \\
R\&D2 & 0.072 & - & & & & \\
CR1 & -0.044 & $-4.66^{*}$ & - & & & \\
EQUITY1 & $0.442^{*}$ & .259 & -.274 & - & - & - \\
EQUITY2 & 0.220 & .104 & $.576^{* *}$ & -.054 & .140 & -.003 \\
SIZE & $0.651^{* *}$ & $-.520^{* *}$ & .363 & .304 & -.043 & $=$ \\
DEBT & 0.177 & .144 & -.252 & .153 & &
\end{tabular}

\section{Regression results}

Based on the previously set model, the results of the econometric analysis of the sample enterprises are shown in the following table:

As can be seen from the above Table III and Table IV, the correlation coefficients between the absolute and relative amounts of equity concentration and R\&D investment are both negative and are significant at the confidence level of $99 \%$ and $95 \%$, respectively, indicating that equity concentration has a strong effect on $R \& D$ investments. For the sample enterprises in the coal-mining industry, the more concentrated equity will dampen the enthusiasm of enterprises for $\mathrm{R} \& \mathrm{D}$ investments, which also indicates that the empirical results are inconsistent with $\mathrm{H} 1$.

The correlation coefficient between the degree of equity counterbalance and absolute and relative amount of $R \& D$ investments are all positive, but the impact on the former is not significant, and the impact on the latter is significant at the confidence level of $90 \%$. The improvement of degree of equity counterbalance in the coal-mining industry does not play a significant role in promoting firms' $R \& D$ investments, nor does it have a negative effect on firms' R\&D investments when the degree of equity counterbalance is too high, but only partially verifies the $\mathrm{H} 2$. The nature of equity is positively correlated with the absolute and relative amount of $R \& D$ investments, and is significant at the confidence level of $95 \%$, indicating that state-owned enterprises in the coal-mining industry have higher R\&D investments than non-state-owned enterprises.

\section{Discussions}

Firstly, the degree of ownership concentration has a negative impact on R\&D investments. Generally speaking, the more concentrated the equity, the greater the individual shareholder's control and influence over the enterprise, and the easier it is to reflect the expectations of the enterprises. In this case, the majority shareholder will pay more attention to the long-term operation efficiency of the enterprises, and therefore will strictly supervise the enterprise managers and support the R\&D activities that can bring long-term returns. Therefore, the gradual concentration of equity will play a positive role in $R \& D$ investments.

When the equity is relatively concentrated, the majority shareholder can have the ownership and control rights, and the incentive to obtain the latter is often greater than the former. Therefore, there will be a negative correlation between the majority shareholder and $R \& D$ investments. However, the single largest share of listed companies in China's coal-mining industry is represented by the high holding share of state-owned shares, so this explanation of 
negative correlation between the two is obviously not applicable.

TABLE III: REGRESSION RESULTS WITH R\&D INVESTMENTS AS DEPENDENT VARIABLE

\begin{tabular}{cccc}
\hline \hline Variables & Coefficient & t statistic & p value \\
\hline \hline C & 8.3286 & 3.5783 & 0.0019 \\
CR1 & 0.0412 & 2.8814 & 0.0092 \\
EQUITY1 & 0.0072 & 0.5551 & 0.5850 \\
EQUITY12 & 1.2652 & 2.5812 & 0.0178 \\
SIZE & 0.5565 & 4.8036 & 0.0001 \\
DEBT & 0.3482 & 0.3832 & 0.7056 \\
$\mathrm{R}^{2}($ Adj R \\
D-W value $^{2}$ & $0.6568(0.5710)$ & & \\
\hline F- statistics (Probability)-7.65510(0.0003). &
\end{tabular}

F- statistics (Probability)- 7.65510(0.0003).

TABLEIV: REGRESSION RESULTS WITH R\&D INTENSITY AS THE DEPENDENT VARIABLE

\begin{tabular}{cccc}
\hline \hline Variables & coefficient & $\mathrm{t}$ statistic & $\mathrm{p}$ value \\
\hline \hline $\mathrm{C}$ & 0.2027 & 4.0056 & 0.0007 \\
CR1 & -0.0007 & -2.2513 & 0.0358 \\
EQUITY1 & 0.0005 & 1.9325 & 0.0676 \\
EQUITY12 & 0.0271 & 2.5380 & 0.0196 \\
SIZE & -0.0074 & -2.9570 & 0.0078 \\
DEBT & -0.0080 & -0.4036 & 0.6908 \\
$\mathrm{R}^{2}\left(\right.$ Adj R $\left.{ }^{2}\right)$ & $0.6113(0.5142)$ & & \\
D-W value & 2.7320 & &
\end{tabular}

F- statistics (Probability) - 6.2920(0.0012).

Secondly, the proportion of state-owned enterprises is too large, and only 3 out of 26 are non-state-owned enterprises, which results in higher monopoly and lower competition in the product market. The price of coal-mining enterprises' products is not determined by the market mechanism but is determined by the relevant authorities of the government. In addition, the demand price elasticity of coal-mining products is low, the sensitivity of market demand to price changes is also low, and the state or the government supervises the stateowned enterprises in terms of pricing and fixed production. As a result, the majority state-owned shareholders may lack the awareness of survival risk brought by competition, which makes the promotion effect of high ownership concentration on the increase of R\&D investments not to be exerted. Generally speaking, the larger the controlling share of stateowned shares of coal-mining enterprises, the easier it is to get policy support. On the contrary, the failure of a firm's decision to invest in $R \& D$ will lead to the decline of its performance and even bankruptcy. Due to the high controlling share of major shareholders, they need to assume more risks and responsibilities, indicating that the major shareholders may not actively invest in R\&D activities.

Thirdly, $\mathrm{H} 2$ is partially verified. That is, when the equity is relatively concentrated, the improvement of the degree of equity counterbalance has a positive effect on $R \& D$ investments. This relationship is not significant, indicating that it has not had a significant effect on promoting $R \& D$ investments. For the above mentioned state-owned enterprises, the higher the degree of equity concentration, the more likely it is to lead to internal control. If there are small and medium shareholders with certain equity at the same time, they can supervise the managers and urge them to actively operate, which will have a positive impact on the decision-making of $R \& D$ investments. Due to the stateowned nature of the enterprise, small and medium-sized shareholders are not able to compete for control rights. What they care about is the maximization of ownership income.
When they have considerable ability, they will have the enthusiasm to supervise the managers. Moreover, there will not be any negative impact on the R\&D investments due to the internal struggle caused by the excessively high degree of equity counterbalance. Therefore, there is a positive correlation between the two, rather than an inverted "U" relationship.

Fourthly, contrary to hypothesis H3, the R\&D investment of non-state-owned enterprises is weaker than that of stateowned enterprises. The government plays a leading role in the development of the coal-mining industry. From a macro perspective, China is vigorously promoting the construction of an innovative country. The traditional pattern of production and mining modes of coal-mining enterprises does not meet the requirements of the concept of "sustainability" and accelerating the pace of technological innovation in the coal-mining industry is a new policy proposal to adapt to the new era. Moreover, the difference of products in the coalmining industry is relatively small, and the effect of coalmining enterprises' innovation of production mode to realize safe and clean operation cannot be significantly displayed on the products. Therefore, the state-owned coal-mining enterprises are more responsive to the policy than the nonstate-owned enterprises. Moreover, the technological innovation of coal-mining enterprises mostly involves the improvement and research and development of large-scale production equipment and new production modes. So, the capital required for technological innovation is huge. Compared with non-state-owned enterprises, state-owned enterprises have greater financial resources and easier access to policy support, capital, and bank credit, so they are better able to carry out $\mathrm{R} \& \mathrm{D}$ investments.

\section{CONCLUSIONS}

Firstly, the empirical results of the coal-mining industry in this paper show that the improvement of ownership concentration is not conducive to the $R \& D$ investments of enterprises, whether in the relative or the absolute control rights. This is mainly because the concentration of coalmining enterprises' equity is manifested as the monopoly of state-owned shares, which to some extent coincides with the research results of the relationship between the state-owned shares and $R \& D$ investments in the existing literature. Under the condition of higher degree of equity concentration, the strengthening of shareholders' counterbalances has a positive effect on R\&D investments. The diversification of investment subjects has prompted enterprises to pay more attention to the maximization of economic benefits rather than the realization of certain social goals.

Secondly, due to the natural monopoly of the coal-mining industry and the macro-policy trend, the state-owned enterprises are more powerful than the non-state-owned enterprises in R\&D investments. Even so, the imperfect equity governance structure still hinders the $R \& D$ investments of the state-owned enterprises, resulting in the low level of R\&D investments in technological innovation. 


\section{REFERENCES}

[1] J. Wu, YLi. "Does factor endowment allocation improve technological innovation performance? An empirical study on the Yangtze River Delta region", Science of the Total Environment. vol. 716, pp. 137107, 2020.

[2] S Ling, G Han, Hunter WC, Li H. "The impact of green credit policy on technological innovation of firms in pollution-intensive industries: Evidence from China", Sustainability. Vol.12, no.11, pp.1-16, 2020.

[3] JL Hervas-Oliver, F Sempere-Ripoll. "Disentangling the influence of technological process and product innovations", Journal of Business Research. Vol.68, no.1, pp.109-118, 2015.

[4] P Shrivastava,S Ivanaj, V Ivanaj. "Strategic technological innovation for sustainable development",International Journal of Technology Management. Vol.70, no.1, pp.76-107, 2016.

[5] M Manzaneque, J Diéguez-Soto, A Garrido-Moreno. "Technological innovation inputs, outputs and family management: Evidence from Spanish manufacturing firms", Innovation Management Policy\& Practice. Vol.20, no.4,2018.

[6] M-H Cho. "Ownership structure, investment, and the corporate value: An empirical analyses", Journal of Financial Economics, vol.47, no.1, pp.103-121,1998.

[7] MH Castro. "The Brazilian bankruptcy law reform, corporate ownership concentration, and risk-taking”, Managerial and Decision Economics. vol. 41, no. 4, pp. 562-573, 2020.

[8] D Shefer, A Frenkel. "R\&D, firm size and innovation: An empirical analysis", Technovation. Vol. 25, no. 1, pp. 25-32. 2005

[9] PX Wang, LJ Zhang, WT Yang. "Empirical study on the ownership structure and results of listed company of the reforms of split share structure", In: 2009 International Conference on Management Science and Engineering - 16th Annual Conference Proceedings, ICMSE 2009.

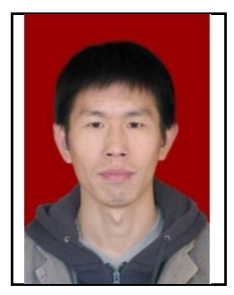

Song Zhi-Hong is a professor in the department of Economics, Institute of Management and Decision, Shanxi University, P. R. China. He received his Master's degree and $\mathrm{Ph}$. D from University of International Business and Economics, P. R. China. His current research interests focus on innovation management, standardization, and sustainable development.

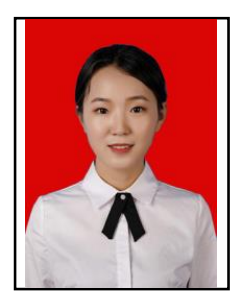

Wang Xue is a postgraduate student in School of Economics and Management, Shanxi University, P. R. China. She received his B. A degree from Qingdao University, P. R. China. Her current research interests focus on innovation management and platform competition.

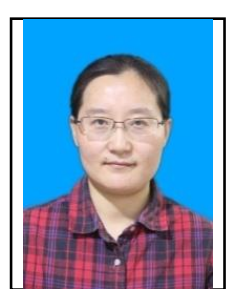

Lee Dong-Mei is an associate professor in the department of Accounting, School of Economics and Management, Shanxi University, P. R. China. She received his Master's degree from School of Mathematics, Shanxi University, P. R. China, and Ph. $\mathrm{D}$ in management from School of Economics and Management, Shanxi University, P. R. China. Her area of specialization is times series analysis, technology management and standard battles. 